\title{
RECENT TRENDS ON TV WHITE SPACE DEPLOYMENTS IN AFRICA
}

\author{
I. Opawoye ${ }^{1}$, N. Faruk ${ }^{2,}$, O.W Bello ${ }^{3}$ and A. A. Ayeni ${ }^{4}$ \\ 1,3 DePARTMENT OF TELECOMMUNICATION SCIENCE, UNIVERSITY OF ILORIN, ILORIN, KWARA STATE. NIGERIA \\ 2DEPARTMENT OF INFORMATION AND COMMUNICATION SCIENCE, UNIVERSITY OF ILORIN, ILORIN, KWARA STATE. NIGERIA \\ ${ }^{4}$ DEPT. OF MATHEMATICS AND INFORMATION SCIENCE, NORTHUMBRIA UNIVERSITY, NEWCASTLE, UNITED KINGDOM \\ Email addresses: 1ifeoluwa.opawoye@gmail.com, ${ }^{2}$ faruk.n@unilorin.edu.ng, 3 laibello@unilorin.edu.ng, \\ 4 ayeni.a@unilorin.edu.ng
}

\begin{abstract}
In this paper, we presented the effects of Television White Space (TVWS) on digital divide in Africa. The trends in digital divide are found to be wide in most African countries, which are characterized with low internet penetration. Perhaps this is expected because over $60 \%$ of people in Africa reside in the rural area and these areas are characterized with low literacy, poverty level and limited telecommunication infrastructure supports. There have been research efforts and regulations towards the secondary use of TV frequencies. However, findings indicate that there are limited opportunities for such system in Europe: This is due to high internet penetration in Europe, but the situation may be quite different in other part of the world like in Africa. Therefore, the TVWS could be used to provide affordable universal access in rural Africa. The paper also presents some benefits developing countries in Africa will incur from utilizing the TVWS solution. Also, recent trend in the deployment of TVWS and experiences got from African countries that embrace the solution are presented.
\end{abstract}

Keywords - TV White space, digital divide, IEEE802.22 WRAN, Africa and Internet

\section{INTRODUCTION}

Information is power, and before mobiles came along, access to data was limited for millions of Africans [1]. While the developed world tends to take the internet for granted, there are plenty of people in Africa who have never felt the click of a mouse button or watched a video on YouTube [2]. Africa's telecommunications market is still at its early phase of development, simultaneously, undergoing a rapid growth rate than the rest of the world. The continent's 650 million mobile phone subscribers even outnumber those in the U.S. and Europe [2]. With this growth comes several wireless communication system and smart phones. With Only 7 percent (7\%) of local households have Internet access, most of which can be found in South Africa, the 15th largest telecoms market in the world as at 2012 [2]. Mobile telephony in the early 2000s in Africa has been growing and is more widespread than the traditional fixed line telephony. African's telecommunication companies are envisaging providing broadband internet access devices as means to facilitate an increase in internet penetration in Africa with the aim of getting Africa closer to the digital divide. There have been tremendous increases in the rate of internet users in Africa in the last 9 years from $2 \%$ to $16 \%$. This phenomenon clearly shows Africa is taking a major step towards reaching the digital divide. When you consider that just $1 \%$ owned a mobile in 2000 , the rate of growth seems all the more astonishing. There are now more than 35 mobile network operators in Africa extending their base station networks to improve coverage [1].

Digital divide is the gap that is used to denote between the persons or countries that have ready access to Information and Communication Technology (ICT) and the sufficient skills to make use of those technology and those who have no skills to make use of the same technology within a given area. Digital divide is subject to information utilization, information accessibility, and information receptiveness. Internet users are people utilizing the internet in the last 12 months from any device, including mobile phones whereas penetration is the percentage of a country's population that is internet users. 


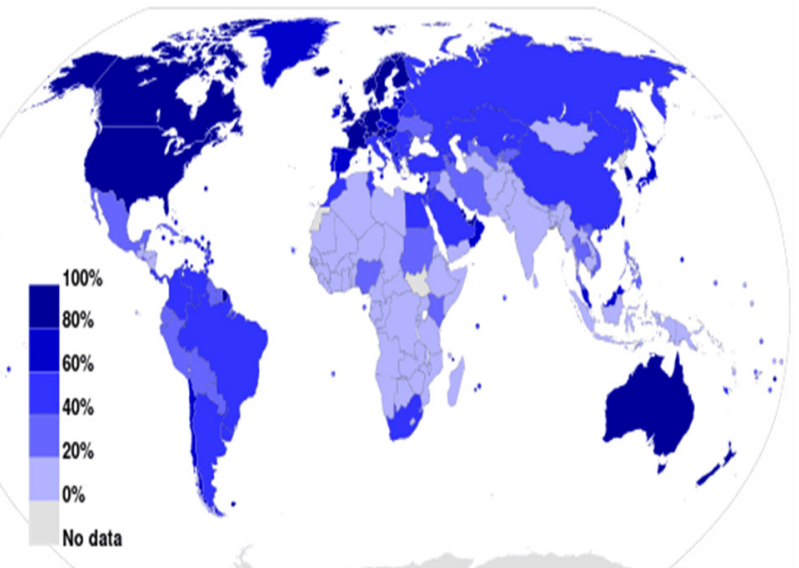

Fig.1. Internet penetration in 2012 [3]

Table 1 . Internet users by region: Data source [4]

\begin{tabular}{lccc}
\hline Year $\rightarrow$ & 2005 & 2010 & 2013 \\
Region $\downarrow$ & $(\%)$ & $(\%)$ & $(\%)$ \\
\hline Africa & 2 & 10 & 16 \\
Americas & 36 & 49 & 61 \\
Arab States & 8 & 26 & 38 \\
Asia and Pacific & 9 & 23 & 32 \\
Common wealth of & 10 & 34 & 52 \\
Independent States & & 67 & 75 \\
Europe & 46 & 67
\end{tabular}

Estimate is based on internet users per 100

\section{inhabitants}

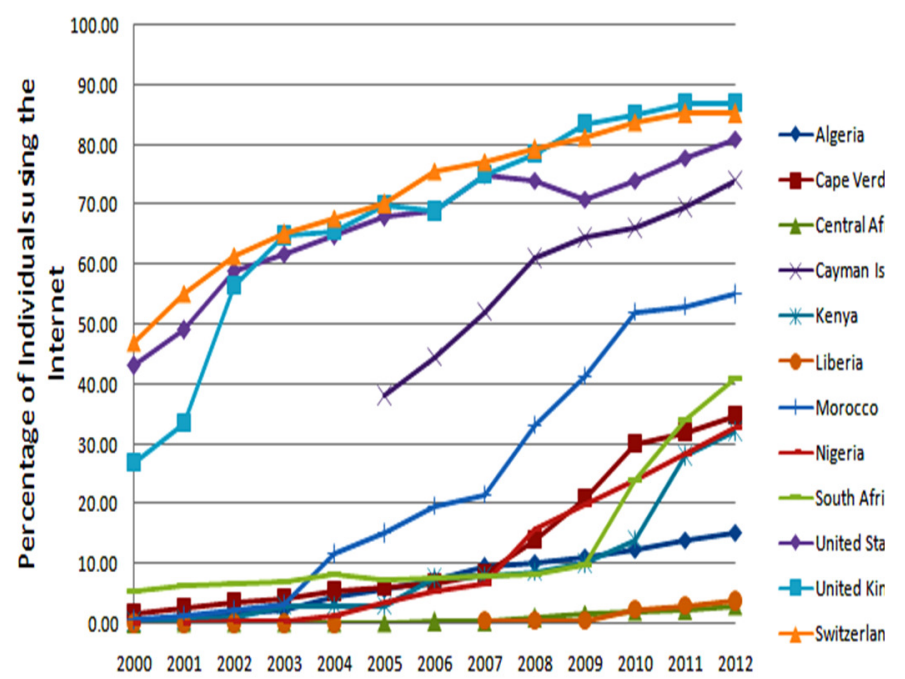

Year

Fig.2. Cross country of internet penetration: Data source [4]

Table 2 gives a list of the cellular Mobile telephone subscriptions and percentage of individuals' using the internet in Africa in the year 2000 and 2012 by International Telecommunication Union (ITU). From Table 2, it can be seen that there has been a huge increase in the mobile Cellular telephone subscriptions and internet users in Africa. Egypt leads the chart while
Rwanda is the lowest as seen from above. Nigeria shows a tremendous increase from 0.06 to $32.88 \%$ along with Cape Verde. The major users that contributed to the above are the people living in the urban compare to the rural areas. Telecommunication companies in Africa are envisaging Broadband Wireless Internet Access technologies as the significant means to make Internet access available to the population at large. Projects are being completed that aim at the realization of Internet backbones, that might help cut the cost of bandwidth in African countries. A good example is TVWS. While Global system for mobile communication (GSM) operators in Africa are thinking of rolling out high speed cellular broadband so as to make available internet access to uncovered areas and complement increase in internet penetration, several ICT companies are in support of bridging the gap between digital divide. Microsoft, Google amongst others have looked for an alternative and cost effective mechanism to bring broadband to rural and other unconnected communities. It is using the so-called TV white spaces, those unused parts of the wireless spectrum usually used for television, to provide internet connectivity [1].

Table 2. Internet penetrations in Africa: Data source [4]

\begin{tabular}{|c|c|c|c|c|}
\hline \multirow{3}{*}{ Country } & \multicolumn{2}{|c|}{$\begin{array}{c}\text { Mobile-cellular Telephone } \\
\text { Subscriptions }\end{array}$} & \multicolumn{2}{|c|}{$\begin{array}{c}\text { Penetration } \\
(\%)\end{array}$} \\
\hline & \multicolumn{2}{|c|}{ Year } & \multicolumn{2}{|c|}{ Year } \\
\hline & 2000 & 2012 & 2000 & 2012 \\
\hline Algeria & 86,000 & $37,527,703$ & 0.49 & 15.23 \\
\hline Angola & 350,000 & $12,785,109$ & 0.11 & 16.94 \\
\hline $\begin{array}{l}\text { Cape } \\
\text { Verde }\end{array}$ & 19,729 & 425,310 & 1.82 & 34.74 \\
\hline Ghana & 130,045 & $25,618,427$ & 0.15 & 17.11 \\
\hline Malawi & 49,000 & $4,646,894$ & 0.13 & 4.25 \\
\hline Nigeria & 30,000 & $112,777,785$ & 0.06 & 32.88 \\
\hline Rwanda & 39,000 & $5,690,751$ & 0.06 & 8.02 \\
\hline $\begin{array}{l}\text { South } \\
\text { Africa }\end{array}$ & $8,339,000$ & $68,394,000$ & 5.35 & 41.0 \\
\hline Kenya & 127,404 & $30,731,754$ & 0.32 & 32.10 \\
\hline Egypt & $1,359,900$ & $96,798,801$ & 0.64 & 44.07 \\
\hline
\end{tabular}

\section{WHY TV WHITE SPACE?}

Considering the low internet penetration as well as the unevenly internet access distribution among countries in Africa. Digital divide has caused some countries to lag behind in technology (even newer technology), democracy, labour and tourism. Furthermore, obstacles to low internet users in Africa includes low computer literacy level, limited telecommunications infrastructures, sustainable energy and most especially 
high cost of internet services. So many inhabitants in this region have little to spend on food than buying data cap for connectivity to the internet. If internet use proliferates in Africa at the rate mobile phones did in the early 2000s, the continent stands to add as much as $\$ 300$ billion to its economic growth by 2025 [1]. Hence the question is, how can TVWS reduce digital divide and increase internet penetration?

The values from Table 2 is without the exploitation of TVWS, if TVWS could be exploited to serve the rural areas, and because of its ability to travel far and reduced cost in communication, then there would be a tremendous increase on the individuals using the internet in Africa.

However, this paper aims at envisaging the effects TVWS will bring in bridging the gap of digital divide which is a function of the low internet penetration in Africa, complementing the aim of connecting the people in the rural areas with the utilization of the vacant spectrum to provide low cost broadband internet service. Please note that TVWS is not wiping out the incumbent operators, but, to complement in bridging the gap in the global digital divide.

\subsection{What is TV White Space?}

TV White spaces are vacant, unused or interleaved frequencies located between broadcast TV channels in the Very High Frequency / Ultra High Frequency (VHF/UHF) range, which can be found between 54 $\mathrm{MHz}$ and $806 \mathrm{MHz}$ [5]. The VHF range includes channels two to thirteen $(2-13)$, located between 30 and $300 \mathrm{MHz}$ on the electromagnetic spectrum, while the UHF range includes channels fourteen to fifty one ( $14-51$ ), located at $300 \mathrm{MHz}$ and above [5]. The merit of propagating at lower frequency is that lower frequencies propagate better over distance and through walls. However the demerit is issue with capacity. It does not carry many users as it propagates. The systems operating in the TV bands are analogue TV with sensitivity value of $-94 \mathrm{dBm}$, digital TV with sensitivity of $-116 \mathrm{dBm}$ and wireless microphone with $107 \mathrm{dBm}$ [7]. In this regard, Federal Communications Commission (FCC) in the United States announced a threshold of $-114 \mathrm{dBm}$ as the criteria for TVWS [8]. The logic behind this is to utilize the unused spectrum of the incumbent systems for secondary access so that white space devices with low power can utilize this spectrum without causing interference with the incumbent systems. The unused Broadcast TV channels vary sparingly from one location to another. The TV White space devices will have the flexibility to sense, operate and log on to unused TV White Space channels. This is possible with the use of a database that houses unused channels called geo-location database technology. What we are saying in essence is that, TV white spaces are very large, dormant spectrum resource that operator could benefit from providing low cost communications. Creating new technologies that will work with this TVWS spectrum with the motive of bridging the gap between digital divide for generations to come. Fig. 4 shows a proposed TVWS architecture to be deployed in Kenya by Google

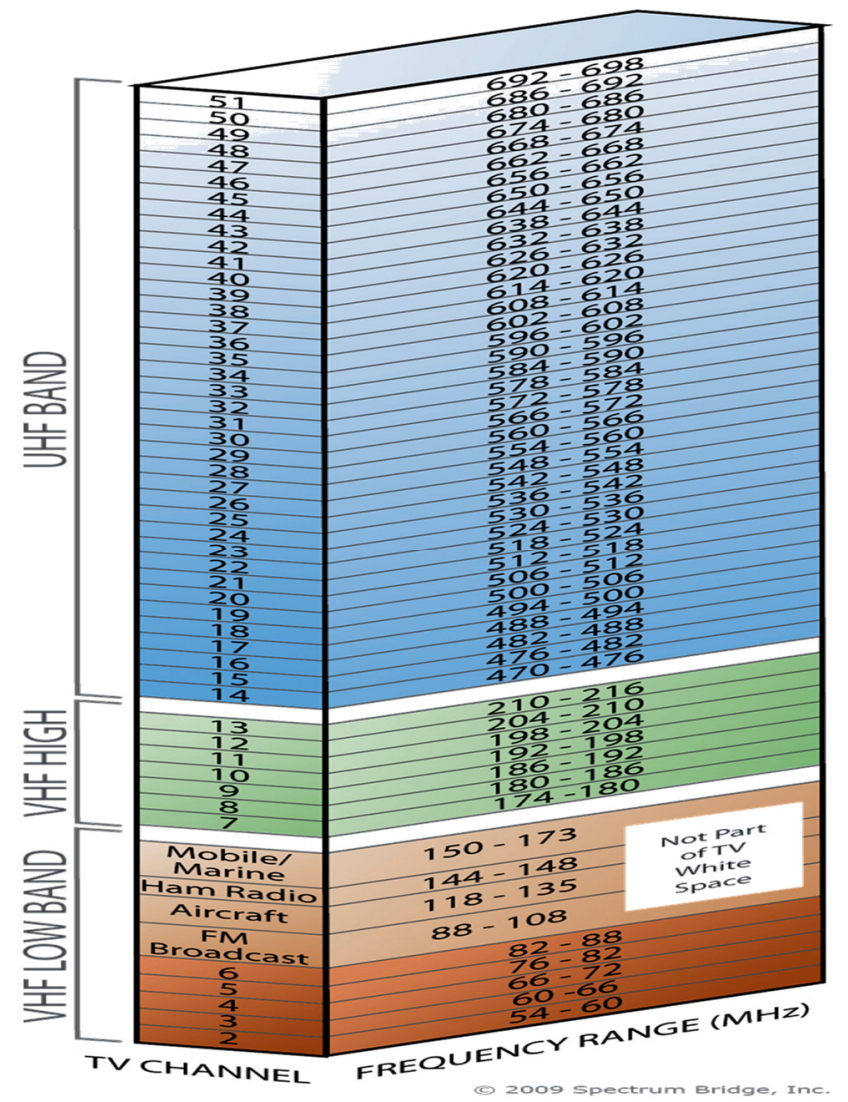

Fig.3. Frequency allocation bands [6]

\subsection{The Significant Benefit that TVWS will bring in Bridging the Gap of Digital Divide in Africa}

For Africa, it seems, necessity may be the mother of invention, but technology is its father [1]. TVWS is an invaluable technology system that could foster the development of Africa's ICT connectivity. When TVWS connectivity is achieved in most African countries, it could supplement end to end broadband internet access coverage of rural and some parts of urban areas in Africa. Internet penetration would improve causing reduction in bridging the gap of digital divide. Information professionals need to teach young people how make to make efficient use of TVWS devices and understand their potential. 


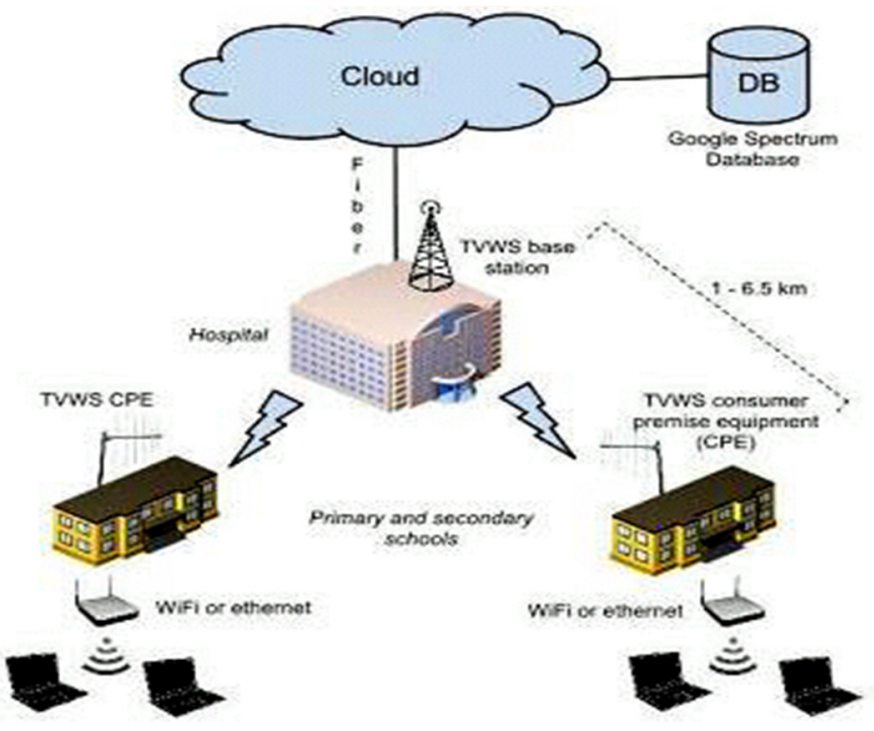

Fig.4. Proposed TVWS deployment Architecture in Africa [9]

Some African countries such as Kenya, South Africa, Malawi and Tanzania have undergone pilot project on TVWS to bring broadband internet access to the rural areas. Ten schools in the Cape Town area in South Africa have been connected to the Internet at speeds of $4 \mathrm{MB} / \mathrm{s}$ using unused UHF spectrum between $480 \mathrm{MHz}$ and $690 \mathrm{MHz}$ of the TV bands [10]. Since the major problem in Africa is sustainable energy, the TV white spaces pilot will use solar-powered base stations to deliver the broadband internet as well as enabling new opportunities for education, commerce, delivery of government services such as TETRA (Truncated Terrestrial Radio) which is used for emergency purposes and also supporting in the area of healthcare services.

The TVWS occupy a spot in the TV band delivering broadband to challenging rural areas and also making patchy urban Wi-Fi network seamless. What we are saying in essence is that, the incumbent operator could incorporate TVWS spectrum to provide seamless connectivity to areas with limited connectivity. According to [10], a TVWS network in the UHF band of TVWS $(600 \mathrm{MHz})$ operating at the same power levels as current Wi-Fi devices ( 40 or $100 \mathrm{~mW}$ ) needs around 16 times fewer access point to deliver the same coverage as $\mathrm{Wi}-\mathrm{Fi}$ in 2GHz.This technology is well suited to provide low cost communication to rural communities with poor telecommunications infrastructure [11]. Other research works that aims to exploit TVWS in Africa are presented in [12] [13] [14] and [15].

\subsubsection{The potential benefits are as follows:}

\subsubsection{Rural and Urban Broadband Deployment:}

The highly favorable propagation characteristics of the TV broadcast spectrum (as compared to unlicensed 2.4 or $5 \mathrm{GHz}$ bands) allow for wireless broadband deployment with greater range of operation (including the ability to pass through buildings, weather, and foliage) at lower power levels. Thus, the TVWS could be used to provide better broadband service in less densely populated areas. Hundreds of urban centers across the nation are already deploying first generation wireless local area networks to provide broadband access to residents. Use of the TVWS for such municipal broadband networks could increase the quality of service and decrease the deployment costs for these networks.

\subsubsection{Public Safety Communication:}

Public agencies can have access to spectrum in the TV band; this would improve the capacity and quality of their networks, as well as facilitate their expanded use for e-government and consumer services. In emergencies, the TVWS can also provide supplementary services to augment public safety communications.

\subsubsection{Education and Enterprise Video Conferencing:}

The TVWS could be used to give local high schools and middle-schools the same multimedia capabilities available to major university campuses: mobile, highspeed Internet access for every student and teacher with a laptop or portable wireless device.

\subsubsection{Personal Consumer Applications.}

TVWS could be used to provide new services and applications to consumers by taking advantage of the improved signal reliability, capacity, and range of the TV broadcast spectrum. Wireless local area networks using low power and battery operated devices could enable new communications technologies that bring safety, convenience, and comfort to consumers in their homes.

\subsubsection{5: Mesh and Ad-Hoc Networks:}

The TV white spaces could be used to enhance mesh networking. Self-configuring, ad-hoc mesh wireless networks avoid disruption or failure by re-routing around node failures or congestion areas, thereby enabling more robust and reliable communications. Mesh networks could be used as backhauls to provide Internet connectivity. 


\subsubsection{6: Security Applications:}

The favorable propagation and bandwidth characteristics of the TV broadcast spectrum could enable enhanced video security applications for commercial, residential, and government purposes. Some examples of security applications using the white space devices include perimeter video surveillance, robust wireless secure area monitoring, and childcare monitoring in the home or in childcare facilities.

\subsubsection{Reduction in Energy Consumption:}

The highly favorable propagation characteristics of the TV broadcast spectrum allow for wireless broadband deployment with greater range at lower transmits power levels. This could, therefore, reduce the number of cell/sites needed to cover a geographical area as compared with the conventional High Speed Packet Downlink Access (HSPDA), Wide Code Division Multiple Access (WCDMA) and Worldwide Interoperability for Microwave Access (WiMAX) systems and subsequently reduce the energy consumption.

\subsection{Challenges of TVWS to internet penetration in}

\section{Africa}

Despite the benefits TV White space could provide, there have been criticisms whether TVWS will provide a better coverage as its licensed spectrum counterpart. With internet penetration of just 16 percent, Africa has long been held back by infrastructure challenges tied to the continent's poverty, vast area and largely rural population. The internet sector's contribution to the gross domestic product is the lowest of all continents at 1.1 percent according to [16].

Secondary use of spectrum is associated with some technical problems. First, the free and vacant frequency bands will need to be identified and carefully monitored using sensitive white space Cognitive Radio (CR). Another is that the secondary usage needs to be handled and monitored in order to avoid interference to the primary user. Maintaining equilibrium between two devices is also paramount to handle interference when different secondary users have detected identical available frequency band. Furthermore, the availability of TVWS spectrum for secondary use is based on the type of network deployment and services that is used.

The usage of TVWS for mobile broadband internet access varies depending on the network deployment. When high towers macro base stations are used, the mobile broadband tends to cause interference on propagating over large distances, causing a reduction in spectrum availability. But if TVWS spectrum is designed to be used for indoor deployment, that means low power base stations will be used, then the secondary usage will cause interference in limited areas resulting into enormous available channels.

Another concern is the usage of the newer technologies. The target audience needs information professionals to teach them how to use these technologies irrespective of the gender, income or traits. If there are no credible information professionals and new technologies are being deployed, digital divide is finding its way back to the continent.

\section{COGNITIVE RADIO (CR) STANDARDS AND ACCESS TECHNIQUES FOR TVWS}

\subsection{The IEEE 802.22 Wireless Regional Area Networks} (WRAN)

According to [17], IEEE announced the publication of the 802.22 standard, which ultimately aims to provide broadband internet access to wide areas around the world, and thus, bringing along reliable and secure high speed communications to rural and even urban communities. IEEE802.22 WRAN standard which stands for Wireless Regional Area Networks (WRANs), and takes merit of the considerable transmission characteristics of the UHF and VHF TV bands to provide broadband internet access across a large area from the transmitter up to $100 \mathrm{~km}$ [17]. It was reported in [18] that individual WRAN Technology will deliver up to 22 Mbps per channel without causing any interference to the reception of incumbent TV stations and thus using TVWS (guard band) between the filled TV channels to avoid overlapping. WRAN technology is useful for serving rural areas where most unused TV channels are located along with the protection that no harmful interference is caused to the current operators. IEEE 802.22 WRAN standard will integrate sophisticated CR functionalities as well as access to dynamic spectrum, incumbent operator database access, accurate and concise geo-location techniques, spectrum policies for optimal use of the available spectrum.

\subsection{IEEE 802.19 and IEEE SCC 41 standards}

The target of IEEE 802.19 standard is the potential development of procedures and capability for coexistence, amongst different networks that will operate in the environment of TVWS channel [19]. The work to do in this group of standard may incorporate developing mechanisms for the sensing of other networks in the TVWS environment. 


\section{TVWS ACCESS TECHNOLOGY}

\subsection{Cognitive LTE-Femtocell over TV White spaces}

As one of the future indoor coverage solutions, LTEFemtocell has proven to be effective as reported in [20]. This technology has been proposed to access the TVWS with low transmit power when successfully deployed in Africa. It can serve as good indoor equipment for the rural area and also urban area. Based on the demonstration in [20], it was said that cognitive LTEFemtocell can potentially provide significant indoor coverage when widely deployed in future wireless networks, providing high capacity, compact system which reduces device count and lower environmental costs.

\section{TVWS DEPLOYMENTS TAKE UP IN AFRICA}

Dynamic Spectrum Alliance (DSA) is a global organization advocating for laws and regulations that will lead to more efficient and effective spectrum utilization in Europe, Asia and Africa, curbing the demerits poised by digital divide. The goal is to make efficient use of this unlicensed spectrum most especially in rural areas where broadband internet access is limited. Microsoft, Google, Spectra Link wireless, Uhuru One, Wave Tek, COSTECH, TENET, Botswana Innovation Hub, Adapt rum among others are the members piloting TV White space in Africa. Some of the commercial pilots are highlighted below.

\subsection{TV White Space in Nigeria}

So far, there is no official TVWS trail or deployments in Nigeria. However, University of Ilorin has engaged Wave Tek, to provide campus wide Wi-Fi and TVWS connectivity across the entire campus and to hostels and dormitories off campus [25]. Eventually coverage will extend to neighboring villages. To ensure high speed Internet, Wave Tek will distribute Synchronous Transport Module-4 (STM) capacity along with deploying TVWS base stations for areas that may be difficult to reach due to its low frequency and the ability to travel far. This technology will be the first TV White Space powered deployment in Nigeria. It will be also one of the largest campus wide Wi-Fi installations in all of Africa.

\subsection{Ghana TV White Space Commercial Pilot}

Microsoft recently announced a commercial pilot in collaboration with Spectra Link Wireless providing low cost and affordable wireless connectivity to students and faculty at universities in Koforidua, Ghana and a linked joint research initiative with Facebook [21].
Spectra Link Wireless will be deploying high speed wireless networks that will cover all Nations University College and Koforidua Polytechnic. The network will use TVWS frequency enabled radios and other wireless technologies to connect campus buildings ensuring they have access to fast broadband internet access.

\subsection{Ten Cape Town schools connected to Web using TVWS}

No fewer than ten schools have been connected to broadband internet service at browsing internet speeds of 4 Mbps using dormant UHF spectrum located between $480 \mathrm{MHz}$ and $690 \mathrm{MHz}$ meant for TV broadcasting service [22]. These schools are part of the first pilot trial in South Africa to study the effects of connecting underserviced regions to the internet using TVWS, which comprises the currently vacant frequencies meant for television broadcasting [23]. It was also announced that the second trial could demonstrate the use of TVWS to connect rural regions in Limpopo. Furthermore, an envisaged third trial will involve machine-to-machine (M2M) communication using TVWS frequencies in a time-division multiplexing, where different signals are sent at different times or the study of the functionality and use of TVWS

Channels with regard to machines only send signals periodically [23].

\subsection{Kenya TV White Space commercial pilot}

Microsoft launched its first pilot project on February 2013, Mawingu, Kenya. This project is among Microsoft larger 4 Afrika initiatives [24]. Microsoft is working with three bodies, the Kenya's ministry of information and communications, Adaptrum (spectrum database manager) and Indigo Telecom Ltd in Mawingu.

\subsection{Tanzania TV White Space commercial pilot}

The Microsoft 4Afrika initiative continued its pilot trial by setting out another deployment of TV white space in partnership with the Tanzania Commission for Science and Technology (COSTECH) and their local ISP UhuruOne, to provide internet access to university students in Dares Salaam, Tanzania [24]. The project is expected to boost the internet facilities of the university by ensuring flexibility and ease of use of internet services with the aim of connecting students both in and off campus. 


\subsection{Malawi TV White Space commercial pilot}

The University of Malawi, in collaboration with the International Centre for Theoretical Physics in Trieste and Malawi Communications Regulatory Authority, has roll out TV white spaces pilot project in the city of Zomba, in southern Malawi. The pilot, which kicked off in September 2013, has connected several institutions, school, hospital, an airport and a research facility [25].

\section{PROBLEMS ASSOCIATED WITH THE ACCESS TO TVWS IN AFRICA}

One major factor that could facilitate the exploitation of the available TVWS and ensure peaceful coexistence is proper planning of the primary users (PUs) and deployment mechanism for the secondary users (SUs). The idea of deploying cognitive radios to exploit TVWS has been faced with so many challenges. The prototype trial test from the United Kingdom, United States of America and other European countries show that the sensing approach (i.e. CR Technology) performs poorly in the present of strong adjacent channels, couldn't reliably able to detect the presence of passive receiver sites, the hidden node problems, cost and energy are all issues. As such, the CR technology may still not be guaranteed for deployment at the present stage as reported in [26, 27]. For this reason, USA in [28] and UK in [29] have completed a general review of alternative spectrum management models for operating conditions of white space devices (secondary users). The geo-location and database approach which is considered as an alternative technique and much short term solution may not be suitable in Africa and some other developing world due to low internet penetration index. In view of the fact that the activities of the TV broadcast system in developing countries are fairly constant, it is reasonable to create a static or semi-static map of the TV spectrum allotments, which would provide the useful information listed earlier and could be used for secondary operation. Several research works are presented in [30-34] which aim to provide flexibility to spectrum access.

\section{CONCLUSION}

In this paper, the effects of TVWS on digital divide and internet penetration in Africa have been provided. It was that only two African countries have penetration of above 40 percent. In terms of regional comparison, it was found that Africa has the lowest penetration of 16 percent compare to Europe's 75 percent. To increase the penetration rate in Africa, there is a need to adopt the concept of frequency reuse, where, unused spectrum allocated to TV broadcast system i.e. TVWS could be exploited. The paper also provide expensive review on the CR standard such as the IEE802.22 WRANs which was designed primarily, to operate effectively in the TV broadcast bands while ensuring that the incumbent operator are protected from interference. Finally, various access technologies and, the deployment and take up in Africa was presented.

\section{REFERENCES}

[1] M. Wall. 2014. "Africa's mobile boom power innovation economy" Available athttp://www.bbc.com/news/busines28061813?oci $d=$ africa outbrain_techbiz [Accessed 1 ${ }^{\text {st }}$ July 2014]

[2] S.Mlot, 2013.A snapshot of internet use in Africa. Available http://www.pcmag.com/article2/0,2817,2426807,0 0.apx [Accessed 4th May, 2014]

[3] ICT facts and figures, ITU 2014. "Internet penetration world map" Available http://www.itu.int/en/ITUD/Documents/statistics/2013/Individual Internet 2 000-2012. xls [Accessed 19th June 2014]

[4] ICT facts and figures, ITU 2014. Available at http://www.itu.int/en/ITUD/Statistics/Pages/facts/ default.aspx [Accessed 14th June, 2014]

[5] K. Andersson, "Using TV White Spaces for Rural Broadband" Carlson Wireless Technologies. white paper. Available at http://www.carlsonwireless.com/products/ruralco nnect- ip.htm [Accessed 14th March, 2014]

[6] Spectrum Bridge Inc. "Introducing TV White Spaces" Available http://www.slideshare.net/search/slideshow?searc hfrom $=$ header $\& \mathrm{q}=$ Introducing $++\mathrm{TV}+$ White + Space s [Accessed 24th June 2014]

[7] N. Faruk, Y.A. Adediran and A.A.Ayeni, "Onthe study of empirical path loss models for accurateprediction of TV signal for secondary usersProgres in Electromagnetic Research (PIER) B, USA, Vol. 49, pp 155- 176, 2013

[8] FCC, "Second report and order and memorandum opinion and order, "ET Docket No. 08-260, Nov. 2008.

[9] Announcing a new TV White Spaces trial in South Africa. Available at

\section{http://google}

africa.blogspot.com/2013/03/announcing-new-tvwhite-spaces-trial-in.html [Accessed 24th, June2013]

[10] Microsoft 4Afrika Initiative, white space project Available at

http://www.microsoft.com/africa/4afrika/white_sp ces project. aspx. [Accessed 23th, June 2013]

[11] Most Promising Applications for TV White Spaces. Available 
http://palgronsund.com/2010/09/24/5-mostpromising-applications-for-tv-white-spaces/ [Accessed 25th, June 2013]

[12] N. Faruk, A.A.Ayeni and Y.A Adediran,"DTV coverage and protection contour estimation for spatial white space" in Proc IEEE International Conference on Emerging \& Sustainable Technologies for Power \&ICT in a Developing Society, pp 96-99, Imo, Nigeria, July $31^{\text {st }}, 2013$.

[13] J. Van de Beek, J. Riihijarvi, A. Achtzehn, and P. Mahonen, "TV White Space in Europe," Mobile Computing, IEEE Transactions on communication, vol. 11, no. 2, pp. 178-188, Feb.2012.

[14] N. Faruk, A.A.Ayeni and Y.A Adediran,"Error Bounds of Empirical Path Loss Models at VHF/UHF Bands in Kwara State, Nigeria" in Proc.IEEE EUROCON conference, Croatia July $1^{\text {st }}-4^{\text {th }}, 2013$, pp $602-607$.

[15] N. Faruk, M. Ali and M. Gumel ,"Interference Mitigation MAC Protocol for Cognitive Radio Networks", Wireless Engineering and Technology(WET), Scientific Research Publication, Inc., USA. Vol. 3, No. 2, 2012, doi:10.4236/ wet.2012.32010

[16] M. Pizzi 2013. Africa on the verge of Internet boom. Available at http://america.aljazeera.com/articles/2013/11/22/ afrca-on-the-vergeofinternetboom.html [Accessed $14^{\text {th }}$ may 2014]

[17] IEEE 802.22 $2^{\mathrm{TM}}-2011$ Standard for Wireless Regional Area Networks in TV Whitespaces Completed. Available at http://www.businesswire.com/ news/home/20110726007223/en/IEEE802.22TM2011-Standard-Wireless- Regional- Area-Networks [Accessed 24th, June 2013]

[18] Using TV Spectrum for Telecommunications http://www.uppersideconferences.com/whitespace 2013/whitespace2013intro.html [Accessed 2oth, June 2013]

[19] First Cognitive Radio Networking Standard for Personal/Portable Devices in TV White Spaces. Available at http://www.ecma. international.org/ publications/files/drafts/tc48-tg1-

2009132.pdf [Accessed 24th June, 2013]

[20] Z.Zhao, L. Univ, Schellmann, M, Boulaaba, H; Schulz, E. "Interference study for cognitive LTE-femtocell in TV white spaces" Available at http://ieeexplore.ieee.org/xpl/login.jsp?tp=\&arnum ber $=6100947$ E-ISBN: 978-92-61-13681-9 Print ISBN978-1-4577-1148-0 INSPEC Accession Number: 12471087

[21] Microsoft research, 2014. "Pilots and demonstration" Available

athttp://research.microsoft.com/enus/projects/spe ctum/pilots.aspx [Accessed 29th May, 2013]

[22] Microsoft 4Afrika Initiative, white space project Available athttp://www.microsoft.com/africa/4afrika/white_s paces_project.aspx. [Accessed 23th, June 2013]

[23] Trial connects Ten Cape Schools to Web using TV White spaces. Available at

http://www.engineeringnews.co.za/article/tvwhitespace-frequencies-trial-to-informdynamicspectrum-allocation-2013-04-12 [Accessed $14^{\text {th }}$ June 2013].

[24] Microsoft unveils TV white space pilot in Tanzania Available at http://www.fiercebroadbandwireless.com/story/mi crosoft-unveils-tv-white-space-pilot-tanzania/201305-08. [Accessed 23rd, June 2013].

[25] Dynamic Spectrum Alliance. 2014. “ Worldwide Trials and Pilots"

http://www.dynamicspectrumalliance.org/pilots.l\# pilots_africa [Accessed 20th June, 2014]

[26] W. Webb, "White Space databases: A guidance note for regulators and others" January, 2012

[27] FCC, "Unlicensed Operation in the TV Broadcast Bands " Report and Order Memorandum Opinion FCC 10-174, Sept 23, 2010

[28] Ofcom, "Digital Dividend: Cognitive Access, Statement Licence-Exempting Cognitive Devices Using Interleaved Spectrum", July, 2009. Available from:

http://stakeholders.ofcom.org.uk/binaries/consulta tions/cognitive/statement/statement.pdf [accessed: 18th Jan., 2012].

[29] N .Faruk, N.T. Surajdeen, O. Kolade and A.A.Ayeni, and Y.A. Adediran, (2014) "DTV protection regions for spectrum sharing" IET Journal of Engineering, Institute of Engineering and Technology, 5th Sept, 2014 